\title{
Correction to: Optimization of Thymoquinone-Loaded Coconut Oil Nanostructured Lipid Carriers for the Management of Ethanol-Induced Ulcer
}

\author{
Usama A. Fahmy, ${ }^{1,4}$ Ahmed L. Alaofi, ${ }^{2}$ Zuhier A. Awan, ${ }^{3}$ Hani M. Alqarni, ${ }^{1}$ and Nabil A. Alhakamy ${ }^{1}$
}

Published online 23 July 2020

\section{AAPS PharmSciTech 2020; Vol. 21, Article 137}

Published: 17 May 2020

DOI: https://doi.org/10.1208/s12249-020-01693-1

When the article was first published, the incorrect image for Fig. 1 was inadvertently uploaded. The authors reviewed their raw data and found that Fig. 1 was not related to nanostructured lipid carrier and was uploaded by unintended mistake. Although replacing the figure will not affect the conclusion of the paper, but scientific honesty requires correcting the mistaken figure with a correct one.

The online version of the original article can be found at https:// doi.org/10.1208/s12249-020-01693-1

\footnotetext{
${ }^{1}$ Department of Pharmaceutics, Faculty of Pharmacy, King Abdulaziz University, P.O.Box: 80260, Jeddah, 21589, Saudi Arabia.

${ }^{2}$ Department of Pharmaceutics, College of Pharmacy, King Saudi University, Riyadh, Saudi Arabia.

${ }^{3}$ Department of Clinical Biochemistry, Faculty of Medicine, King Abdulaziz University, Jeddah, Saudi Arabia.

${ }^{4}$ To whom correspondence should be addressed. (e-mail: uahmedkauedu.sa@kau.edu.sa)
} 
FIGURE 1 - CORRECT

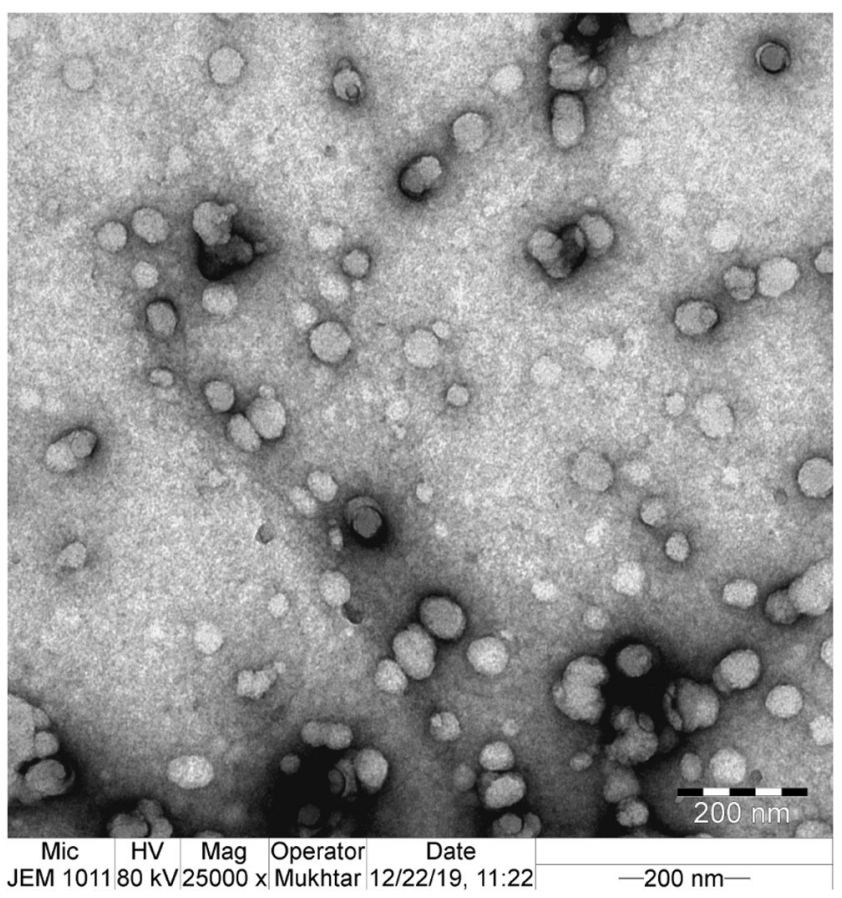

Publisher's Note Springer Nature remains neutral with regard to jurisdictional claims in published maps and institutional affiliations. 